\title{
LA RELACIÓN HOMBRE-ANIMAL EN LA MITOLOGÍA GRIEGA
}

\author{
Bruno Lantero Moreno
}

Madrid

\begin{abstract}
Resumen: El autor analiza la relación hombre-animal en el imaginario griego desde un ángulo concreto, como símbolo de la intervención de lo divino sobre lo humano y como vehículo de expresión de la identidad del hombre en la naturaleza. Los encuentros con los seres híbridos y las metamorfosis en otras especies son un lenguaje profundo de representación, una dimensión de lo sagrado, de aquello que provoca fascinación y terror, que acerca al hombre a situaciones de transición, a un juego de espejos donde el animal es lo otro y donde se desvelan los anhelos del hombre por escapar al encierro de los límites de su condición.
\end{abstract}

Palabras clave: híbrido, sagrado, dioses, metamorfosis, otredad y poesía.

\section{The man-animal relationship in the Greek Mythology}

Abstract: The author analyses the man-animal relationship in the Greek imaginary from a concrete point of view, as a symbol of the intervention of the divine over the human and as a vehicle for the expression of the identity of man in nature. Meetings with hybrid beings and others metamorphose into another species are a deep language of representation, a dimension of what is sacred, of that which causes fascination and terror, which makes man become closer to situa- 
tions of transition, to a mirror game where the animal is the Other and where man's desires of escaping confinement of the limits of their condition is revealed. Keywords: hybrid, sacred, gods, metamorphosis, otherness, poetry.

Recibido: 25/9/2017 Aprobado: 5/11/2017

Dicen que hay un territorio desde donde el hombre comprende las cosas...

\section{Introducción}

Dicen que hay un territorio desde donde el hombre comprende las cosas. Ese territorio puede ser la mitología. O puede no serlo. Nunca se sabe. Su significado es infinito y proviene de un tiempo y un espacio inconmensurable. El mito es un lenguaje poético y, como tal, se expresa con la fuerza alegórica de los símbolos y los sentimientos, aleccionando sobre la vida y sobre el ser humano. Somos entes metafísicos, y en esa necesidad de encontrar la sustancia que reúne la multiplicidad de la realidad, está el mito, está el “bomo mitologicus", está nuestra relación con la naturaleza, y nuestra constante construcción de creencias.

Del infinito catálogo de atributos que tiene el hombre, que decía Spinoza, la mitología es una expresión arquetípica de aquellos atributos que precisamente viven en la profundidad del ser, y que muy probablemente son la causa primera del Homo Sapiens, o quizá de los últimos tiempos de sus antepasados mas remotos, incapaces de concebir fábulas y símbolos trascendentes. La mitología responde así a ese constante anhelo de dar sentido, de encontrar en la experiencia el camino de la divinidad, de fundirnos con nuestro origen, de volver a la casa del padre, de transformar la rutina en rito, de superar el mie- 
do, de "decorarnos". Somos animales raros, complejos y maravillosos, que construimos sentido para vivir, y para abrazar la muerte.

Desde el antiquísimo poema asirio de búsqueda de la inmortalidad de Gilgamesh, presente en todo el mundo griego, el lugar del hombre se encuentra entre el ámbito de la animalidad y de la divinidad, si bien en su esencia hay una pulsión constante y tenaz de transgresión de ambos limites. En ese sentido, Aristóteles ${ }^{1}$ defendía la polis como el estado natural de los hombres al afirmar que el ciudadano que no habita dentro de los límites humanos "o es una bestia bruta o es un dios". Pero el hombre, debido a su inmensa curiosidad, a ese gusto voraz por la diferencia, por mirar al otro lado, por huir, por vivir, se embarca en la transgresión de esos límites, chapoteando en esa tensión constante entre himeros y hybris, entre las pulsiones del deseo y los peligros del exceso. Los animales del imaginario griego se insertan así en estos relatos de experimentación lúdica e imaginaria para expresar su mayor encanto y su poder más poético, y lo hacen junto al hombre que se encuentra en la jerarquía natural por encima de los animales, pero siempre por debajo de los dioses.

Los animales son seres mortales que carecen de conciencia de muerte por estar "atados al palo del instante", y se diferencian de los dioses antropomórficos inmortales griegos en que para éstos la muerte es un imposible. El hombre, como animal, aunque con logos, palabra y razón, también es mortal, pero padece la angustia existencial al ser consciente trágicamente de su fini-

1 Aristóteles, Política I, 1253a. 
tud. Es precisamente porque estamos seleccionados para tratar de sobrevivir y reproducirnos por lo que construimos los mitos, eso que Dodds llama el "pensar onírico del pueblo, frente al sueño concebido como mito del individuo" (1993: 105). Y lo hacemos porque dicha selección implica el desarrollo de la capacidad de cooperación y la transmisión de cultura acumulativa, atributos de nuestra especie frente a los restantes primates que diría Harari, y también porque necesitamos buscar sentido, y encontrar la felicidad. Tanto desde la razón, como desde aquello que está por encima de la razón, la poesía, el hombre, entre la vigilia y el sueño, construye un mundo que lo considera también un mundo real, verdadero, y sagrado, pues siente 'la plenitud del Ser' (Otto, 1917: 9-89). Aun reconociendo nuestra posición en la jerarquía natural, dentro de nosotros, decía Aristóteles, hay no obstante una cosa divina, el intelecto, y en la medida en que se puede vivir en ese nivel de experiencia, podemos vivir como si no fuéramos mortales ${ }^{2}$. A este respecto Zenón, el fundador del estoicismo, fue incluso más lejos al afirmar que el intelecto humano no solamente es afín a Dios sino que "es" Dios, una porción de la sustancia divina en su estado puro o activo (Dodds, 1993: 223).

Se inicia así, desde el observatorio de la configuración mental del mito, y desde el poder trascendente de la razón y de la imaginación, el recorrido íntimo de una relación: la de los animales y los hombres. Y se hace sin pretensiones. Por supuesto no entraré en la expresión de lo inefable, pero tampoco simplificaré lo que no es simple. Dice Kundera que la memoria es

2 Aristóteles E.N. 1177 24-1178a: el hombre es "quasi mortales deus" 
una forma de olvido, pero es lo que tenemos, y buscaremos en las fuentes griegas los recuerdos de aquel tiempo del mito.

El animal es un compañero enigmático de viaje, es vehículo de expresión, es el otro polo del umbral, el que nos separa y el que nos encuentra. El hombre en los mitos se confronta con lo animal en relatos de batallas y muertes heroicas, y en viajes y aventuras peligrosas; y lo hace allí donde, como decía Pitágoras, "nada conserva su apariencia, y la naturaleza, renovadora del mundo, rehace unas figuras a partir de otras; [donde] el universo entero, créeme, nada parece; sino que cambia y renueva su aspecto". ${ }^{3}$ Es en este territorio de tránsito donde se devela el cosmos, donde, como dice Homero en la Ilíada "Océano es el origen de todas las cosas", ${ }^{4}$ siendo así el agua atributo esencial por tanto de la vida y origen común de los humanos y de los animales. De este mito de Océano posiblemente Tales de Mileto inferirá que es ese elemento primigenio el principio material del todo precisamente por su capacidad de mutación y adaptación. El universo mental griego pasa así por esta sabiduría y conocimiento 'acuoso' y flexible con el que el hombre aplica la astucia y la inteligencia, descrito con el nombre de mễtis ${ }^{5}$ : como dice Frontisi-Ducroux, "es un modo de aprehensión de los acontecimientos dúctil y poliformo", un saber que poseerán algunos personajes de los mitos, como Ulises (Odiseo en griego), Circe o Proteo, y con el que, frente al animal, sabrán moldearse a la ondeante movilidad del mundo (2009: 279).

3 Ovidio (2015): 256-255.

4 Homero (2012): 246.

5 Detienne y Vernant, 1988. 
El hombre, perseguido por una realidad oculta y desconocida ante la que se muestra diferente y extraño, se enfrenta inevitablemente a la naturaleza y especialmente a los animales bajo una consigna de misterio: el esplendor de los dioses ${ }^{6}$, siempre presente, ilumina sus gestas y esa luz toma la forma de imágenes sagradas "como si en la conciencia humana palpitase la sensación de algo real". ${ }^{7}$ Así, la prosa poética de María Zambrano nos dice, en este sentido, que los dioses griegos se manifiestan como la luz del alba:

¿Quién no ha visto en la claridad de la mañana, en la danza perfecta que es la metamorfosis, una pluralidad de figuras que dibujadas y desdibujadas, no se corporeizan, transformándose infatigablemente? Nacen y se deshacen; se enlazan y se retiran; se esconden para reaparecer como el hombre juega a hacer cuando es niño o cuando juega a esos juegos en que la infancia se eterniza: música, poesía. ${ }^{8}$

6 Aquellos que "no comen pan ni toman vino como los hombres; por eso tampoco fluye sangre por sus venas, sino el fluido de un elemento celeste-eterno" (Homero, 2012: 339).

7 Citado por Otto, 1996: 12, "En su libro Las variedades de la experiencia religiosa dice, casi ingenuamente, William James, cuando alude al origen de los dioses griegos: «No entro a examinar cómo han nacido los dioses griegos. Pero todos nuestros ejemplos conducen a la siguiente conclusión: la representación de algo que existe objetivamente, representación más profunda y válida que cualquiera de las sensaciones aisladas y singulares, por las cuales, según la opinión de la psicología contemporánea, se atestigua la realidad.”

8 Zambrano, 1955: 29. 


\section{Encuentros sagrados}

Son los dioses los que posibilitan la contemplación de la naturaleza, ya que ellos son los que revelan aquel algo sagrado, y en la concepción griega son, por tanto, los animales - los arboles o los ríos- una expresión de la unidad y de la pluralidad de los dioses, es decir, de la 'identidad' en la 'contradicción' y de la 'permanencia' en el 'cambio'. ' Cuando los animales pueblan los mitos los relatos nos hablan de los encuentros de los animales con los hombres como una modalidad de intervención de lo divino sobre lo humano. Ya sean perros, ruiseñores, leones, cerdos, tábanos, centauros, serpientes, toros o animales alados que nos recuerdan la coexistencia de dos seres en uno solo, la relación con el hombre se produce siempre fuera de los santuarios, en el día cotidiano, al margen de los templos y de los centros de los ritos sagrados. En esos recintos los dioses están representados por suntuosos animales, por victimas sacrifícales, con los que están íntimamente asociados: ciervos y cabras para Apolo y Artemisa, toros para Zeus y Poseidón, palomas para Afrodita o carneros para Hermes, pero es en la acción del relato mítico, en esa mentira que dice la verdad, ${ }^{10}$ donde los dioses fluyen y se mueven, donde atraviesan la materia para entrar en comunión con los hombres, deslizándose con la animalidad de alguna especie. En raras ocasio-

9 Liberal, 2003: 16.

10 Ya Teón (Spengel: 72), en el siglo I o II d. C., definía la fabula como "un relato fingido que ofrece una imagen de la verdad", valiosas reflexión desde antiguo sobre el juego simbólicoliterario entre lo real y lo imaginario. 
nes la metamorfosis es a la inversa: en la antropogonía hesíodica de Éaco, que explica, por ejemplo, que los primeros habitantes de la ciudad de Egina se originaron a partir de la metamorfosis de las hormigas de la isla; hormigas que se convierten en hombres es también el caso del origen de los Mirmidones, los guerreros que lucharon en Troya a las ordenes de Aquiles. En el primer caso es la insufrible soledad de Éaco lo que hace que Zeus se apiade, y en el segundo, son las características de valentía, tenacidad, instinto social y capacidad de trabajo del insecto las que, si seguimos lo que indican las fabulas de Esopo, configurarían el elemento de racionalización del mito.

Pues bien, es en esos encuentros fuera de los santuarios de la época mítica y simbólica, en los que el antiguo terror del animismo mágico y del totemismo había sido ya espiritualizado, donde los animales del imaginario griego se muestran en todas sus formas: como híbridos monstruosos o bestias salvajes, como dóciles y domesticadas criaturas, o en muchas ocasiones, como seres que con la metamorfosis les arrancan el cuerpo al hombre, de forma brusca o por etapas, introduciéndose bajo su envoltura. Es en ese rico hábitat de formas y de expresiones que se invaden las barreras de las especies y se traslada al hombre a lo profundo, para enseñarle el camino y para guiarle en la búsqueda de lo que es más suyo: su propia identidad.

Los dioses nos conocen, y saben bien de nuestros anhelos y excesos, saben de nuestra curiosidad y de la necesidad tenaz que tenemos de escapar al encierro de nuestros cuerpos. Y para ello nos acercan a los animales para transmutar, florecer y sucumbir, para atravesar los umbrales, y para cambiar de conciencia. La naturaleza se muestra así a la distancia y en cercanía, en un juego de espejos donde el hombre y el animal se miran. De esta forma, con 
los animales se aprende que, a veces, la existencia esta al borde de un abismo, porque su suerte depende de la voluntad del hombre, o de Artemisa, como les ocurre a los animales del bosque, otras, porque son seres limítrofes y fronterizos que se disfrazan de caos o de luz, como los híbridos, y otras, porque son seres que nos anticipan con la metamorfosis la expresión de un transito, de un cambio de categoría, brutal, a veces irreversible.

Los animales, por tanto, aun encontrándose en lugares profanos, siempre están tocados por lo sagrado y nos trascienden a un territorio místico de unidad con la naturaleza, alejado de lo mundano. Lo sagrado, dice Salvador Paniker, "es un atributo que le da profundidad a la mirada, no permitiendo que el mundo sea un espacio plano" (2015: 49). El animal con sus múltiples formas se relaciona así con el hombre bajo la luz divina, esa que Otto llama 'la conciencia viva de un ser superior' (2017: 37), que intentara dar explicación, o confort, al terror de la vida y de la muerte a través de la fabulación.

Dichos encuentros, fuera de los recintos sagrados, están descritos en numerosos fuentes narrativas como los poemas homéricos, en los que los dioses manifiestan su poder adoptando formas de animales (Atenea en lechuza o golondrina, etc.) o humanas por inspiración religiosa o mítica; hay mudadores de forma como el 'cambiante' Proteo, o dioses-magos como Circe, ${ }^{11}$ que transforma y degrada la naturaleza del hombre en animales de forma, como veremos, especialmente dolorosa. Otros relatos, como el de Aedón, la hija de Pandáreo, que es convertida para siempre en ruiseñor, explican además 
implícitamente, la creación de una especie. ${ }^{12}$ En Hesíodo la conversión en animales adquiere generalmente una dimensión mas humana, al servir las metamorfosis para castigar o premiar las conductas de los hombres (Forves Irving, 1992: 12). En el helenismo, están las colecciones sistematizadas como la Biblioteca de Apolodoro o las Metamorfosis de Antonino Liberal con un preponderante carácter etiológico, es decir, que intentan explicar la causa de seres y especies o sus cualidades. Es la magia poética del latino Ovidio, que se inscribe directamente en la tradición griega, el que sitúa el género de la metamorfosis en su cima literaria.

\section{El híbrido fronterizo}

Los encuentros con dos seres híbridos, en concreto, ilustrarán el lenguaje simbólico que lleva al hombre a un lugar de transición. Del barro acuoso que quedo después del gran diluvio nace un animal primigenio que hunde sus raíces en culturas míticas mesopotámicas, la serpiente, uno de los seres con mayor y más constante carga simbólica del imaginario griego. Desde el neolítico, la notoriedad de su naturaleza metafórica, que rivaliza con la de los propios dioses inmortales, tiene una explicación precisa: allí donde el mas famoso aforismo griego proclamaba los designios de la mitología ("conócete a ti mismo"), en Delfos, se consagra también la hazaña del gran mito universal de Apolo, el dios arquero, que debe matar a la Serpiente Pitón, el dragón-

12 Homero, 2012: 610 y ss. 
híbrido primordial, eterno, inmortal. ${ }^{13} \mathrm{Si}$ bien el simbolismo mítico de la serpiente es la perversión y el terror no espiritualizado-sublimado, la imaginación exaltada, la vanidad culpable y el principio del mal, que dirá Paul Diel, el mito se vale de una estratagema que adapta y muta el símbolo: agrega a la serpiente real el atributo de ser un animal fabuloso, domado, exterminado (Diel, 1986: 83), en este caso por el dios Apolo, con lo que el relato mítico nos habla en puridad de algo diferente. Nos habla de la fuerza de la luz y de la verdad que 'vence', es decir, 'absorbe' e 'incorporara' ${ }^{14}$ a otra fuerza, también de luz, símbolo de la fuerza femenina de la Madre Tierra, de 'la Magna Mater Universal'. La gran Pitón ${ }^{15}$ es hija de Temis ("La Justicia”) que tenía dedicado un santuario a la diosa de la Tierra, Gea, su madre; la serpiente, así, es una manifestación de poder divino, un ser numinoso, proveniente de numen, termino éste entendido como ser sagrado supremo al que tienden todas las religiones, según Otto, como símbolo de daimon ${ }^{16}$ vincula-

13 Ovidio: 2015: 438-451.

14 Como lo hizo también Heracles con el monstruoso León de Nemea que al abrazarlo y matarlo 'lo incorporo', muestra de lo cual será la utilización de su piel como armadura.

15 Buhigas, 2015: Del nombre de la serpiente derivará Pitonisa ("la Divina”) la más famosa sacerdotisa del santuario de Apolo en las montañas de la Fócida, que según los romanos entraría en trance por los vapores subterráneos conocidos como el "aliento de la Serpiente Pitón".

16 Agathos Daimon: En griego, "demonio bueno". Generalmente sirve para denominar a un numen innominado, al que se considera benigno y propicio. Después de las comidas era frecuente ofrecer una libación de vino al agathos daimon, que también era considerado protector del hogar, atribuyéndosele en este caso figura de serpiente. En el Egipto helenístico se desa- 
do a la fuerza espiritual de la Tierra, a la "Virgen Negra". Al tiempo que mata, la serpiente da la vida ${ }^{17}$ y es símbolo de la espiritualidad universal, de la sabiduría y conocimiento de aquel que tiene los secretos de la vida y de la muerte $^{18}$.

En otros relatos del mito, el animal híbrido se disfraza de enmascaramiento, de Centauro o de Sátiro y, solos o junto con Dioniso, el Perturbador, trastean por el cosmos con la violencia y la embriaguez desbocada de una nueva consciencia irracional. Dioniso, el dios del vino que inspiró a un Hölderlin o un Nietzsche en sus últimos y mas profundos pensamientos, es el que busca la animalidad mas extrema para situarnos, junto a Apolo, 'entre lo bello y lo siniestro', en la encrucijada mas creativa. En esos terrenos limítrofes de lo animal y lo humano, hay un reino de la alteridad que realmente une mundos e invade la normalidad, traspasando las paredes del más complejo laberinto. Lo sabe bien el Minotauro, que vive en soledad, confinado allí, en el silencio ensordecedor de un territorio sombrío ("nada se parece tanto a Dios como el silencio", dice Eckhart). El genuino monstruo masculino con cabeza de toro nacido de la unión ilícita y antinatural de un humano con un animal nos dará sorpresas, y su poder simbólico universal

rrollo el culto del agathos daimon como "serpiente benéfica"... (Diccionario de Religiones Comparadas, 1975: 90).

17 La serpiente enroscada y domada vertiendo en una copa veneno, llamado 'pharmakon', es el símbolo de Esculapio, dios de la salud (Diel, 1986: 85).

18 Aun vencida la serpiente ha sido símbolo de animal maligno por la tradición gnóstica que llega a interpretar la imagen de la Virgen María pisando la serpiente como afirmación de su condición de diosa (Cf. Buhigas). 
atravesará las tinieblas de cada generación. El vengativo Poseidón hizo que Pasífae, la mujer del rey de Creta (el desagradecido Minos que osó dar la espalda a los dioses creyéndose señor y no súbdito, a modo de un "superhombre") fue presa de la apasionada atracción hacia un toro blanco que con el engaño y la técnica de Dédalo logró consumar. El Minotauro fruto de esa pasión, que es un ser estéril ${ }^{19}$ e irracional, alejado de la civilización y recluido en lo mas hondo de la consciencia, fue vencido por el héroe ateniense Teseo que "hallo al Minotauro en la parte mas recóndita del laberinto, lo mato luchando a puñetazos y salió recogiendo el hilo (Apolodoro, Epitome, 1.9) ${ }^{20}$, el hilo de Ariadna, la bella hija de Minos que luego será la reina del sequito dionisiaco.

Imposibles mas atributos poéticos en el imaginario para convocar infinitas versiones que descubran la relación del hombre con un híbrido animal, ello sin incluir la expresión poética del ave, del deseo vital de las alas de Ícaro que la continuación del mito nos llevaría a la imaginación sublime de los ángeles, o a la inspiración de las Musas de un Pegaso. Procedente de la Atenas ejemplar, del prototipo de la paideia, el héroe Teseo se enfrenta, así, al Minotauro, que se diferencia del hombre a partir de sus semejanza con el, confrontando la poderosa presencia de lo otro, al que abate, y quien sabe si antes de incorporarlo, de matarlo, ese hijo del mar Egeo parpadeo con un

19 Los monstruos son naturalezas mezcladas que reúne dos physeis, una humana y otra animal que según Platón son seres que no se asemejan a sus padres en el sentido de que se apartan de las características de su especie (Cratilo, Pl. 394a).

20 Apolodoro, Biblioteca (3.1.3). 
doble sentimiento: con inquietud por su defecto, por su diferencia, produciéndole un fuerte extrañamiento que le empujara a apartarse, o bien con absoluta fascinación por su semejanza, por su afinidad, produciéndole una identificación que le animara a integrarlo, a abrazarlo. El hombre, que precisa de la distancia y de la alteridad para definirse, encontraría su identidad por su oposición a los demás y por el contraste con lo ajeno. Se habría desplegado así en este relato un complejo territorio de espejos donde el hombre se mira en la imagen del animal, y viceversa ${ }^{21}$. Habría durado un segundo, o quizá mas. Quién sabe.

\section{El viaje de la metamorfosis}

Si nos alejamos del hibrido, que a veces en lo iconográfico es un modo metonímico de representar la transformación completa, el animal del mito nos acercaría a un nuevo juego de expresión, al milagro de la metamorfosis de los cuerpos que nos permitirá explorar las fronteras entre humanidad y animalidad. Quizá sea aquí donde anide la mayor conexión y la mayor repulsión, donde la conciencia que puede tener el ser humano de su especificidad obtenga necesariamente su mayor lucidez en una confrontación con lo animal. El imaginario griego colectivo incluye infinidad de metamorfosis en animales, desde las cíclicas de las divinidades marinas, como Nereo o Tifón, a las de los propios dioses sobre su propia apariencia en sus encuentros con los hombres. Un ejemplo sería Atenea cuando se convierte en golondrina

21 Bonnefoy, 1981: 219-234. 
para desaparecer de la escena en la que está 'disfrazada' de Mentor con Ulises, o Zeus, en sus aventuras amorosas, conquistando a la casta cazadora Calisto o a la fenicia Europa. Esta modalidad de la acción de lo divino sobre lo humano produce un cambio de status, de especie o de categoría, y nos permite explorar las fronteras entre humanidad y animalidad en un viaje de transformación. La concepción fluida y movediza del mundo, de comunión y unidad con la naturaleza, característica del mundo antiguo, será un correctivo del universo de los límites y de la clasificación aristotélica que establece una gradación sin vuelta de la planta al animal y al hombre. La metamorfosis será, así, un espectáculo de aprendizaje para el hombre que, en comunión con la naturaleza, habrá de entender a los animales siempre en continuidad con su entorno.

Los animales del imaginario griego incluidos en la Iliada y en la Odisea nos trasladan, con la forma de la narrativa de las metamorfosis de sus cuerpos, a una concepción específica del tiempo, a un modo de 'aprehensión' del mismo que es diferente de la que se da cuenta en las Metamorfosis de Ovidio. En la épica homérica la metamorfosis de hombre en animal se narra como un acto instantáneo, relampagueante, como un puro rapto, que se produce en un simple pestañeo, sin recorrer el proceso de cambio. Es el caso de la doncella Io que en un abrir y cerrar de ojos se convierte en ternera blanca por mediación de Zeus, o la sustitución instantánea de la joven Ifigenia en su sacrificio por una cierva del bosque de Artemisa, y que dará comienzo a la guerra.

El elemento central en el poema de Ovidio, en cambio, es precisamente la duración del cambio, su evolución, la maleabilidad y el sufrimiento de las 
transformaciones que experimentan esos cuerpos. La ceguera inconsciente del proceso de transición que caracteriza el tratamiento de los textos homéricos refleja, como dice Frontisi-Ducroux "un modo de aprehensión 'entrecortada' del tiempo mas que un continuum, donde la vida de cada individuo no se vive tanto como una evolución regular desde el nacimiento hasta la muerte sino como una superación de una serie de estadios, de edades, puntuadas por rituales sociales y marcadas por status diferentes" (2008: 279).

En Ovidio la transición del proceso de metamorfosis se relata, en cambio, a cámara lenta, recreándose en el continuum, acompañando la vista por todo el proceso de cambio, en la evolución detallada de la percepción de la mutación de los cuerpos. Aquí la aprehensión del tiempo es diferente, sin etapas, duradera y línea. Este tratamiento narrativo, elocuente a nivel no solamente formal, lo vemos en los cuerpos en transformación de los aludidos compañeros de Ulises que en su encuentro con la diosa hechicera Circe en la isla Ea beben del maléfico bebedizo que ella les ofrece, aun habiendo sido advertidos a su llegada del peligro con la presencia de una manada de lobos y leones mansos.

Aquí en las Metamorfosis el relato es casi cinematográfico:

...empecé a erizarme de cerdas, a no poder ya hablar; a emitir en vez de palabras, un gruñido ronco y a inclinarme con todo el rostro a tierra, y note que la boca se me endurecía en curvo hocico, que el cuello se me hinchaba de músculos, y con los miembros con los que hacia poco cogía la copa, con esos mismos caminaba; y 
con los demás, también victimas (tanto pueden los brebajes), soy encerrado en la pocilga..."22

En la Odisea, el suceso se narra sin recrearse en la mutación, si bien añadiendo un dato doliente:

...al punto los golpeo con una varita y los encerró en las pocilgas. De cerdos tenían ya las cabezas, la voz, el pelo y el cuerpo, aunque su mente permanecía tal como antes ${ }^{23}$.

La metamorfosis instantánea que aplica la maga a los compañeros del astuto Ulises, también es aquí en indignos cerdos — lo que delata sus viciossi bien ahora en su degradación a animales les conserva el elemento que precisamente les diferencia: la conciencia. En esta metamorfosis en lugar de producirse un transito radical, se produce un descenso en la escala tan solo del plano formal, en la superficialidad de sus cuerpos, quedando como un nuevo tipo de hibrido entre lo humano y lo animal. Esta animalización con conciencia humana, donde florece lo instintivo que llevamos dentro, plantea muchas cuestiones sobre nuestra verdad ontológica. En la versión que de este episodio nos narra Apolonio de Rodas las criaturas que produce no son cer-

22 Ovidio, 2015: 276-286.

23 Homero, 2004: 239-242. 
dos, leones y lobos sino seres informes "de una naturaleza imposible de ver", resultados de mezclas de trozos de distintas especies.

Ulises, asistido por Hermes, y dotado de mêttis, de prudencia, de esa sabiduría para resistirse, para moldearse a la cambiante movilidad del mundo, no caerá en dicha transformación (aunque en cierto modo sucumbe a los encantos amorosos de la hechicera), como no lo hizo tampoco Menelao disfrazándose de foca para oponerse a Proteo, ni Peleo instruido por el centauro Quirón para saber conquistar a la diosa Tetis con su poder metamórfico. Los compañeros de Ulises caen porque "representan la humanidad desvalida, irreflexiva, que vive todavía en 'la auto-culpable minoría de edad' de la que hablara Kant, para quien la figura de Ulises/Odiseo vendría a adquirir rasgos prometeicos, al ser el salvador de los hombres, no solo de 'sus hombres', sino de una humanidad que necesita emanciparse" (Goñi, 2012: 165).

Por otra parte, el hombre ha de aprender a integrarse en el equilibrio de su especie y debe superar, por tanto, las fases de transición de la vida, respetando los límites entre lo humano y lo divino. En este sentido, particular atención se presta a este delicado proceso en el mito del nieto de Apolo, Acteón, que es metamorfoseado en ciervo por la ofendida Artemisa, la diosa más antigua de los animales, que le castiga cruelmente invirtiendo la norma que gobiernan las relaciones entre humanos y animales. Existen varias versiones del relato del joven cazador, instruido por el estético centauro Quirón, pero en todas ellas es despedazado por los colmillos de sus propios perros y devorado por estos en un indigno e inquietante espectáculo, a causa de su hybris (desmesura). Este relato nos muestra la jerarquía alterada, invertida, la 
de unos perros eficaces y auxiliares que se convierten en salvajes depredadores de su amo, alegando con ello la restitución del orden y la civilización.

Con el relato de Acteón estamos hablando del característico comportamiento del cazador joven en relación con la actividad cinegética, actividad que se correspondería con un periodo de pruebas que debe ayudar al joven a acceder a la edad adulta. El territorio de la caza, se configuraría, así, en el lenguaje del mito, como un lugar de confrontación de los humanos con las fieras salvajes; como dice Frontisi-Ducroux "sería un espacio terrestre que, como el universo marino, linda con el de los hombres, aunque esté separado de las ciudades por el área de las tierras cultivadas. Este espacio y sus habitantes son propiedad de Artemisa, que regula su equilibrio velando tanto por la reproducción de los animales, como, por otra parte, por la de las hembras humanas, y vigilando que se respete la cuota de matanzas" (2008: 101). En esta interpretación, el hombre ha de aprender a respetar el orden y el equilibrio de la divinidad ecologista, para lo que deberá dominar sus instintos de juventud sin invadir el ámbito de los dioses ni el de las bestias.

\section{Condusión}

Desde este ángulo específico que hemos elegido para tratar la relación hombre-animal en el imaginario griego, donde existe un tránsito continuo y una trascendente expresión de la naturaleza, la animalidad se despliega para el hombre como elemento relevante de un lenguaje simbólico, a veces alec- 
cionador, que revela el latir constante de nuestra condición humana y la necesidad de superar nuestros propios limites.

El animal interviene así en los relatos del mito como presencia sagrada 'construida' para iluminar la misión y la identidad del hombre. Como dice Piaget, "el mundo no es una percepción, sino una interpretación; todas las verdades son interpretaciones, y todas las interpretaciones son construcciones, y [no lo olvidemos], el ser humano solo conoce lo que puede construir".

\section{Bibliografia empleada}

\section{Estudios sobre el tema:}

A. Bernabé y J. Pérez de Tudela, (eds.) Seres hibridos en la mitología griega, Madrid, Circulo de Bellas Artes, 2012.

Y. Bonnefoy, (ed.) [1981], Diccionario de las Mitologías (vol. II), trad. J. Portulas y M. Solana, Barcelona, ed. Destino, 1996.

J. Buhigas. Vídeo "Mitos y arquetipos universales", publicado el 3 de febrero de 2015. https://www.youtube.com/watch?v= ICyGAygIna8.

W. Burkert, Religión Griega. Arcaica y Clásica. Trad. Helena Bernabé, Madrid, Adaba Editores, 2007.

J. Campbell, Los Mitos, Trad. Miguel Portillo, Barcelona, Kairós, 2014.

J. Campbell, El héroe de las mil caras. Psicoanálisis del mito, Trad. Luisa Josefina Hernández, Madrid, Fondo de Cultura Económica, 2017.

L. Cencillo, Mito. Semántica y realidad, Madrid, Biblioteca de Autores Cristianos, 1970.

M. Detienne, y J.P. Vernant, Las artimañas de la inteligencia. La Metis en la Grecia antigua, Trad. A. Piñeiro, Madrid 1988. 
La relación hombre-animal en la mitología griega

P. Diel, Dios y la divinidad, Trad. Ligia Arjona, México, Fondo de Cultura Económica, 1986.

P. Diel, El simbolismo en la mitología griega, Trad. Mario Sanz, Barcelona, Editorial Labor, 1976.

Diccionario de Religiones Comparadas, Volumen 1. Madrid, Ediciones Cristiandad, 1975.

E.R. Doods, Paganos y Cristianos, Trad. J. Valiente Malla, Madrid, Cristiandad, 1975.

E.R. Doods, Los griegos y lo irracional, Trad. Maria Araujo, Madrid, Alianza Universidad, 1993.

M. Eliade, Mito y Realidad, Barcelona, Editorial Labor, 1981.

P.M.C. Forbes Irving, Metamorphosis in Greek Myths, Oxford, 1992.

F. Frontisi-Ducroux, El hombre-ciervo y la mujer-araña. Figuras Griegas de la metamorfosis. Trad. Maysi Veuthey, Madrid, Adaba Editores, 2006.

C. García Gual, Mitos, Viajes, Héroes, Madrid, Fondo de Cultura Económica, 2014.

C. Goñi, Cuéntame un Mito, Barcelona, Ediciones Ariel, 2012.

Y.N. Harari, Homo Deus. Breve historia del mañana, Trad. J. Ros, Barcelona, Debate, 2016.

W.F. Otto, Los dioses de Grecia, Trad. Rodolfo Berge y Adolfo Murguía, Madrid, Siruela, 2012.

W.F. Otto, Dioniso, Trad. Cristina García Ohlrich, Barcelona, Herder Editores, 2017.

R. Otto, Lo santo y lo irracional en la idea de Dios, Trad. F. Vela Madrid, Alianza Editorial, 1996.

S. Paniker, Filosofia y Mistica. Una lectura de los griegos, Barcelona, Editorial Kairos, 2000.

S. Pániker, Cuaderno Amarillo Barcelona, Literatura Random House, 2015.

R. Pániker, Invitación a la sabiduría, Trad. Angels Canadell, Barcelona, Circulo de Lectores, 1998.

F. Rodríguez Valls, Orígenes del hombre, Madrid, Biblioteca Nueva, 2017. 
Bruno Lantero

M. Zambrano, [1955] El hombre y lo divino, México (reimp. 1986).

\section{Textos Clásicos.}

Apolodoro, Biblioteca Mitológica, Madrid, Editorial Akal, 1987.

Homero, Odisea, Trad. C. García Gual, Madrid, Alianza Editorial, 2004.

Homero, La Ilíada, Trad. L. Segalá Estalella, Barcelona, Juventud, 2012.

Liberal Antonino, Metamorfosis, Ed. De José Ramón del Canto, Madrid, Akal, 2003.

L. Spengel, Rhetores Graeci, vol. II.

Ovidio, Metamorfosis, Trad. A. Ramírez de Verger y F. Navarro, Madrid, Alianza Editorial, 2015.

\section{Bruno Lantero Moreo \\ bl@obtspain.com}

